\title{
Monitoring System, Evolution and Prognosis in Renal Patients on Haemodial- ysis Infected by Severe Acute Respiratory Syndrome Coronavirus 2
}

\section{Gustavo Aroca ${ }^{1,2, *}$, Santos-Ángel Depine ${ }^{1,3}$, María Vélez-Verbel ${ }^{2}$, Daniela Dianda ${ }^{4}$, Liliana Gomez ${ }^{5}$, Manuel Cueto Chaparro ${ }^{6}$, Juan Conde ${ }^{1}$, David Vélez-Verbel ${ }^{7}$, Nathalia Cotes ${ }^{5}$, William Peña Vargas ${ }^{8}$, Stefani Chartouni-Narvaez ${ }^{9}$, María Raad $^{10}$, Andrés Cadena-Bonfanti, ${ }^{1,2}$, and Carlos Guido Musso ${ }^{11}$}

\author{
${ }^{1}$ School of Health Sciences, Universidad Simón Bolívar, Barranquilla, Colombia \\ ${ }^{2}$ Clinica de la Costa, Barranquilla, Colombia \\ ${ }^{4}$ Faculty of Economic Sciences and Statistics, University Nacional de Rosario, Rosario, Argentina \\ ${ }^{5}$ Department of Nephrology, Clinica Centro, Barranquilla, Colombia \\ ${ }^{6}$ Department of Nephrology, Clinica Iberoamérica, Barranquilla, Colombia \\ ${ }^{7}$ Faculty of Internal Medicine, Universidad Metropolitana, Barranquilla, Colombia \\ ${ }^{8}$ Nephrology Postgraduate Studies, Universidad Simon Bolivar, Barranquilla, Colombia \\ ${ }^{9}$ Faculty of Medicine, Universidad Simon Bolivar, Barranquilla, Colombia \\ ${ }^{10}$ Faculty of Internal Medicine, Universidad del Sinú, Montería, Córdoba, Colombia \\ ${ }^{11}$ Department of Physiology, Instituto Universitario del Hospital Italiano, Buenos Aires, Argentina
}

${ }^{3}$ Confederation of Dialysis Associations (Confederación de Asociaciones de Diálisis) of the Argentine Republic, Federal Capital, Argentina

*Corresponding author: Gustavo Aroca Martinez, Faculty of Internal Medicine and Nephrology, Universidad Simón Bolívar, Clinica de la Costa, Carrera 50 \#80-90, Barranquilla, Colombia, Phone: +57 3164352749; E-mail: garoca1@unisimonbolivar.edu.co

Received: 03 Apr, 2021 | Accepted: 26 Apr, 2021 | Published: 04 May, 2021

Citation: Aroca G, Depine SA, Vélez-Verbel M, Dianda D, Gomez L, et al. (2021) Monitoring System, Evolution and Prognosis in Renal Patients on Haemodialysis Infected by Severe Acute Respiratory Syndrome Coronavirus 2. Int J Nephrol Kidney Fail 7(1): dx.doi.org/10.16966/23805498.209

Copyright: (c) 2021 Aroca G, et al. This is an open-access article distributed under the terms of the Creative Commons Attribution License, which permits unrestricted use, distribution, and reproduction in any medium, provided the original author and source are credited.

\section{Abstract}

Aim: The novel coronavirus disease 2019 (COVID-19) was first described in Wuhan, China, in December 2019. It has since spread worldwide, leading to high morbidity and mortality. Patients with chronic renal failure on dialysis who also have a confirmed diagnosis of active infection represent a risk group because infections are the second cause of death in this group, followed by immunosuppression caused by the weakening of the innate immunity by uremic toxins. This study aimed to describe the clinical characteristics of patients undergoing haemodialysis who also have a confirmed diagnosis for COVID-19 and its association with short-term outcomes.

Methods: This retrospective study recruited adult patients undergoing permanent renal replacement therapy with a confirmed diagnosis of COVID-19 through a polymerase chain reaction test on nasopharyngeal swabs. It was conducted from May to October 2020 at two private hospitals of Barranquilla, Colombia.

Results: 56 patients were registered with stage 5 chronic kidney disease and COVID-19 disease. The average patient age was 62 years, $66 \%$ were male, and $45 \%$ were on dialysis for hypertensive nephropathy. Although $37 \%$ presented with residual diuresis, this did not influence the results. Furthermore, $95 \%$ of cases were hypertensive, $30 \%$ diabetic, $20 \%$ heart disease, $12 \%$ chronic obstructive pulmonary disease and $12 \%$ obesity. The most frequent symptoms were dyspnea (86\%) and fever (54\%). $80 \%$ of the patients were assigned imaging scores of 4 and 5 based on the COVID-19 Imaging Reporting and Data System imaging classification. In addition, $9 \%$ of cases required invasive mechanical ventilation and $23.2 \%$ of the cases died.

Conclusion: We conclude that patients with permanent chronic kidney disease on dialysis are more vulnerable to developing complications and die due to COVID-19.

Keywords: COVID-19; Haemodialysis; SARS-CoV-2; Chronic kidney disease; Infectious disease

\section{Introduction}

The novel coronavirus disease 2019 (COVID-19) was first described in Wuhan, China, in December 2019. It has since spread worldwide, leading to high morbidity and mortality, in addition to economic and social collapse, and was declared a pandemic on 11 March, 2020 [1].
According to the Center for Disease Control and Prevention and the World Health Organization, the global mortality rate associated with COVID-19 ranges from $0.3 \%$ to $10 \%$ among different populations [2]. These values could be affected by differences in age, fragility and existing comorbidity, showing worse outcomes for patients with 
comorbidity diagnosis such as arterial hypertension, diabetes mellitus, chronic obstructive pulmonary disease (COPD), cancer and chronic kidney disease [3].

In addition, patients with chronic renal failure on dialysis represent a risk group on their own because infections are the second cause of death in this group owing to their secondary immunosuppression that is caused by the weakening of their innate immunity by uremic toxins and associated malnutrition. Furthermore, these patients present a higher amount of proinflammatory cytokines in their peripheral blood, which is accompanied by an increased expression of Tolllike receptors in monocytes and granulocytes, resulting in increased inflammation and tissue dysfunction. In addition to this, there exist comorbidities and "logistic" exposures because these patients need to visit haemodialysis centers 3-4 times per week which increases the vulnerability of this patient group [4,5].

Therefore, these individuals are more susceptible to SARS-CoV-2 infections and to be associated with developing complications such as acute respiratory failure, arrhythmias and shock of different etiologies (i.e., distributive, cardiogenic, obstructive and hypovolemic shock). Shock is the first cause of death in 7\% of cases of COVID-19 and a contributing factor in $33 \%$ of the patients. Among renal patients on haemodialysis, global mortality ranges from $23 \%$ to $30.5 \%$, mainly in elderly patients and in those who have been dependent on treatment for a longer time. According to data from the available literature, one of every four patients on dialysis with COVID-19 will not survive [6,7].

This is why, for this group of patients and their healthcare providers, the greatest efforts must be directed at prevention, strengthening all structural biosecurity measures and all logistical stages related to their treatment, including transfers from and to medical centers [8]. However, some of these recommendations are impossible to follow in Latin America because of vast inequalities in terms of health access and lack of resources $[9,10]$.

Although COVID-19 has been described as being more severe to this group of patients, the factors affecting its development and prognosis are not yet fully known and further evidence is still needed. In this research, we present the experience of a fourth-level medical center with patients undergoing chronic haemodialysis who also presented with COVID-19. We describe and correlate factors associated with poor prognosis and mortality in this population group.

\section{General Objective}

The aim of this study is to describe the clinical characteristics of patients undergoing permanent renal replacement therapy such as haemodialysis, with a confirmed diagnosis of COVID-19 and its association with short-term outcomes.

\section{Material and Methods}

\section{Study design}

This retrospective study included adult patients with stage 5 chronic kidney disease undergoing permanent renal replacement therapy such as haemodialysis with a confirmed diagnosis of COVID-19 through polymerase chain reaction (PCR) test on nasopharyngeal swabs. This study was conducted from May to October 2020 at two state-of-the-art private hospitals located in Barranquilla, Colombia.

We registered data about patients' baseline characteristics, clinical evaluation at the moment of diagnosis, laboratory parameters, radiological findings and short-term results. The information was collected by nephrologists who reviewed patients' medical records. The radiological images were evaluated by a specialist who classified the patterns that were found according to the classification by COVID-19 Imaging Reporting and Data System (CO-RADS) [11].

The basic characteristics of patients included demographic data (age and sex), cause of admission to dialysis and length of treatment, presence of residual diuresis and presence of co-morbidities (diabetes, hypertension, heart disease, obesity and COPD).

Regarding the clinical presentation of a patient at the moment of diagnosis, the presence or absence of the following symptoms was registered: fever, cough (productive or nonproductive), headache, diarrhea, vomiting, dyspnea, fatigue, myalgia, ageusia and anosmia. The application of any assisted ventilation method (invasive or noninvasive) was also registered.

Laboratory tests were performed on the first day of hospitalization and were repeated during a follow-up period, according to the directions from the treating doctor. The data extracted from the results included the count of white blood cells, neutrophils, lymphocytes, haemoglobin, platelets, prothrombin time, international normalized ratio (INR), partial thromboplastin time, glycemia, creatinine, blood urea nitrogen, urea, sodium, potassium, chlorine, calcium, magnesium, aspartate aminotransferase (AST), alanine aminotransferase (ALT), total bilirubin (direct and indirect), lactate dehydrogenase (LDH), D-dimer, C-reactive protein, ferritin and troponin I.

The X-ray patterns were analyzed from the images available from $\mathrm{X}$-rays or tomographies of the thorax, following the directions of the doctor who treated them at the beginning of the hospitalization.

Patients were followed from the beginning of their hospitalization until their deaths or discharge from the hospital, with these two factors being the variables of the analyzed outcome. Hospital release was determined by the cure of the clinical illness.

\section{Statistical analysis}

Quantitative variables are summarized in mean and standard deviation (SD) or median and interquartile range (IQR). Qualitative variables are summarized through absolute, relative and percentage frequencies. Quantitative variables among groups defined by the outcome were compared through t-test comparison of two means in independent samples or Mood's median test. Qualitative variables were compared through the Chi-squared test for association or Fisher's exact test. Associated probability values lower than 0.05 were considered statistically significant.

\section{Results}

Over the period studied, 56 patients were registered in any of the two referred hospital centers with stage 5 chronic kidney disease. They were undergoing a permanent renal replacement therapy such as haemodialysis and had a PCR test positive for COVID-19.

\section{Basic characteristics}

Table 1 reports the basic characteristics of the analyzed group of patients. Patients' average age was 62 years (51-69.5). The youngest patient was 31 years old and the oldest was 83 years old. The composition of the group of patients by sex was $66 \%$ men and $34 \%$ women.

The most frequent cause of hospitalization for dialysis was hypertensive nephropathy in $45 \%$ of cases. This was followed in importance by a combination of diabetic renal disease with hypertensive nephropathy (21\%) and exclusive diabetic renal disease (12\%). The average duration of the dialysis treatments was 39.5 months (24-63). The most recent patient had been treated for 3 months and the oldest had been treated for 13 years. 
Table 1: Basic characteristics of patients included in the study.

\begin{tabular}{|c|c|c|}
\hline Characteristic & \multicolumn{2}{|c|}{ Summary } \\
\hline Age (years), Mean(SD) /Median(IQR) & \multicolumn{2}{|c|}{59.9 (12.6) / 62.0 (51.0-69.5) } \\
\hline \multicolumn{3}{|c|}{ Sex, count (\%) } \\
\hline Male & 37 & $(66.1)$ \\
\hline Female & 19 & (33.9) \\
\hline \multicolumn{3}{|c|}{ Cause of hospitalization in dialysis, count (\%) } \\
\hline Hypertensive nephropathy (HTA) & 25 & $(44.6)$ \\
\hline Diabetic renal disease (DBT) & 7 & $(12.5)$ \\
\hline $\mathrm{HBP}+\mathrm{DBT}$ & 12 & $(21.4)$ \\
\hline Glomerulonephritis & 4 & $(7.1)$ \\
\hline Chronic uropathy & 3 & $(5.4)$ \\
\hline $\mathrm{HBP}+$ Chronic uropathy & 2 & (3.6) \\
\hline Others & 3 & $(5.4)$ \\
\hline $\begin{array}{l}\text { Length of dialysis (months), Mean (SD) / } \\
\text { Median(IQR) }\end{array}$ & \multicolumn{2}{|c|}{$\begin{array}{c}46.3(33.15) / 39.5(24.0- \\
63.0)\end{array}$} \\
\hline Residual Diuresis, count (\%) & 21 & $(37.5)$ \\
\hline \multicolumn{3}{|c|}{ Co-morbidities, count (\%) } \\
\hline HBP & 53 & $(94.7)$ \\
\hline DBT & 17 & $(30.4)$ \\
\hline Heart disease & 11 & $(19.7)$ \\
\hline COPD & 7 & (12.5) \\
\hline Obesity & 4 & (7.1) \\
\hline
\end{tabular}

HBP: High Blood Pressure, DBT: Diabetes Mellitus, COPD: Chronic Obstructive Pulmonary Disease.

Approximately $37 \%$ of patients had residual diuresis. As for comorbidities, hypertension was the most frequent, being observed in $95 \%$ of patients. Diabetes mellitus (30\%), heart disease (20\%), COPD $(12 \%)$ and obesity (7\%) were observed to a lesser extent.

\section{Clinical manifestations and laboratory parameters at the beginning of hospitalization}

The most frequent symptom at the beginning of hospitalization was dyspnea, observed in $86 \%$ of cases. The second most frequent symptom was elevated body temperature, registered in $54 \%$ of patients, followed by nonproductive cough in $41 \%$ of cases. Diarrhea, ageusia and anosmia were less frequent symptoms, presented in at least $10 \%$ of cases (Table 2).

Regarding radiological findings, over $80 \%$ of patients were assigned imaging scores of 4 and 5 according to CO-RADS classification. About $59 \%$ of the patients were category 5 and $23 \%$ were category 4 . There were no patients belonging to category 2 , and the remaining $18 \%$ were equally divided between categories 1 and 3 .

Half of the hospitalizations were registered in the Emergency Care Unit of the hospital centers, whereas the other half was either admitted to the general room (30\%) or to the intensive care unit (ICU) (20\%).

Approximately $32 \%$ of patients required noninvasive assisted ventilation at the beginning of the hospitalization, and an additional $9 \%$ required invasive mechanical ventilation; thus, a total of $41 \%$ of patients required assisted ventilation) (Table 2).

Table 3 reports the median (IQR) of the analyzed laboratory parameters in patients at the beginning of their hospitalization.
Table 2: Symptoms and radiological characteristics at the beginning of hospitalisation.

\begin{tabular}{|c|c|c|}
\hline Characteristics & \multicolumn{2}{|c|}{ Count (percentage) } \\
\hline \multicolumn{3}{|c|}{ Symptoms } \\
\hline Dyspnea & 48 & $(85.7)$ \\
\hline Fever & 30 & $(53.6)$ \\
\hline Nonproductive cough & 23 & (41.1) \\
\hline Fatigue & 18 & $(32.1)$ \\
\hline Myalgia & 13 & $(23.2)$ \\
\hline Productive cough & 10 & $(17.9)$ \\
\hline Vomiting & 7 & (12.5) \\
\hline Headache & 6 & $(10.7)$ \\
\hline Diarrhea & 5 & (8.9) \\
\hline Ageusia & 5 & (8.9) \\
\hline Anosmia & 4 & $(7.1)$ \\
\hline \multicolumn{3}{|c|}{ CO-RADS Pattern } \\
\hline 1 & 5 & (8.9) \\
\hline 2 & 0 & $(0.0)$ \\
\hline 3 & 5 & $(8.9)$ \\
\hline 4 & 13 & $(23.2)$ \\
\hline 5 & 33 & $(59.0)$ \\
\hline \multicolumn{3}{|c|}{ Admission Unit } \\
\hline Emergency care & 28 & $(50.0)$ \\
\hline Hospitalization & 17 & (30.4) \\
\hline ICU & 11 & (19.6) \\
\hline \multicolumn{3}{|c|}{ Assisted ventilation } \\
\hline Invasive & 5 & $(8.9)$ \\
\hline Noninvasive & 18 & (32.1) \\
\hline
\end{tabular}

\section{Outcome}

The patients' follow-up ended with a hospital discharge in $77 \%$ of patients and with an in-hospital death rate of $23.2 \%$ in the remaining patients (Table 4).

Table 5 shows the comparison of basic characteristics, symptoms and laboratories among discharged patients and deceased patients. Deceased patients represent an older age than the discharged patients. Among the deceased patients, a higher percentage of men than women were observed, although differences did not show significance.

Among co-morbidities, only the presence of COPD showed a significant association with the outcome, this one being more frequent among deceased patients. Regarding symptoms, a significant association was found between the outcome and the presence of headaches, which were also more frequent among deceased patients. Myalgia and fatigue were also more prevalent symptoms among deceased patients, although there was no significant difference.

The CO-RADS classification of radiological findings showed a higher frequency in category 4 and 5 patients among the deceased. However, differences among groups were not statistically significant.

The need to administer assisted ventilation, whether invasive or not, was more frequent among patients who passed away, although only one significant difference was detected in the case of noninvasive ventilation.

Among laboratory parameters, significant differences were found between both groups in the count of white blood cells, neutrophils and lymphocytes. White blood cell count was significantly lower 
Table 3: Laboratory parameters at the beginning of hospitalization.

\begin{tabular}{|c|c|c|c|c|}
\hline \multirow{2}{*}{$\begin{array}{l}\text { Laboratory parameters } \\
\text { White blood cells }\end{array}$} & \multirow{2}{*}{$\mathbf{N}$} & \multicolumn{2}{|c|}{ Median (IQR) } & \multirow{2}{*}{$\begin{array}{c}\text { Reference values } \\
4.500-11.000 \times \mathrm{mm}^{3}\end{array}$} \\
\hline & & 5100 & $(14.9-9300.0)$ & \\
\hline Hemoglobin (g/dl) & 51 & 10.7 & $(9.2-11.6)$ & $13-16 \mathrm{~g} / \mathrm{dl}$ \\
\hline Platelets & 51 & 194000 & $(122500.0-261500.0)$ & $150.000-450.000 \times \mathrm{mm}^{3}$ \\
\hline Neutrophils & 50 & 2861.5 & $(71.5-6634.5)$ & $1.800-6.400 \times \mathrm{mm}^{3}$ \\
\hline BUN mg/dl & 50 & 51.4 & $(36.1-70.0)$ & $9-20 \mathrm{mg} / \mathrm{dl}$ \\
\hline Creatinine (mg/dl) & 49 & 8.3 & $(6.5-11.1)$ & $0.6-1.2 \mathrm{mg} / \mathrm{dl}$ \\
\hline Sodium (mmol/l) & 47 & 138 & $(135.3-141.5)$ & $137-145 \mathrm{mEq} / \mathrm{l}$ \\
\hline Potassium (mmol/l) & 47 & 5 & $(4.5-5.7)$ & $3.5-5.1 \mathrm{mEq} / \mathrm{l}$ \\
\hline Lymphocytes & 46 & 416 & $(26.62-897.5)$ & $1.200-3.600 \times \mathrm{mm}^{3}$ \\
\hline Chlorine & 44 & 103.5 & (99.7-108.4) & 98-107 mEq/I \\
\hline C-reactive Protein & 39 & 32.4 & $(9.0-52.2)$ & 0-1 mg/dl \\
\hline $\mathrm{LDH}(\mathrm{U} / \mathrm{L})$ & 36 & 416.7 & $(303.0-533.2)$ & $120-246 \mathrm{U} / \mathrm{L}$ \\
\hline TP (seg) & 27 & 12.6 & $(11.7-14.3)$ & $9.1-12.1 \mathrm{seg}$ \\
\hline INR & 19 & 1 & $(1.0-1.1)$ & - \\
\hline TTP (seg) & 27 & 32 & $(30.0-39.5)$ & $25-45 \mathrm{seg}$ \\
\hline Troponin I (0-0.03 ng/ml) & 27 & 0.1 & $(0.0-0.2)$ & $0-0.03 \mathrm{ng} / \mathrm{ml}$ \\
\hline Blood sugar (mg/dl) & 26 & 116.5 & $(95.0-146.7)$ & $70-105 \mathrm{mg} / \mathrm{dl}$ \\
\hline Urea (mg/dl) & 26 & 130.6 & (93.3-178.5) & $15-38 \mathrm{mg} / \mathrm{dl}$ \\
\hline D-dimer & 24 & 469 & $(149.6-1858.5)$ & $0-255 \mathrm{ng} / \mathrm{ml}$ \\
\hline Ferritin & 22 & 462.9 & $(211.2-1285.2)$ & $20-250 \mathrm{Ug} / \mathrm{L}$ \\
\hline GOT & 20 & 32 & $(24.7-61.2)$ & 17-59 UI/L \\
\hline GPT & 19 & 27 & $(18.3-59.5)$ & 11.4-44.53 UI/L \\
\hline Total Bilirubin (mg/dl) & 17 & 0.7 & $(0.5-0.9)$ & $0.2-1.3 \mathrm{mg} / \mathrm{dl}$ \\
\hline Direct Bilirubin (mg/dl) & 16 & 0 & $(0.0-0.2)$ & $0.0-0.3 \mathrm{mg} / \mathrm{dl}$ \\
\hline Indirect Bilirubin (mg/dl) & 16 & 0.2 & $(0.1-0.4)$ & $0.0-1.1 \mathrm{mg} / \mathrm{dl}$ \\
\hline Magnesium (mg/dl) & 11 & 2.1 & $(1.7-2.2)$ & $1.6-2.3 \mathrm{mg} / \mathrm{dl}$ \\
\hline Calcium & 7 & 8 & $(1.1-9.0)$ & $8.4-10.2 \mathrm{mg} / \mathrm{dl}$ \\
\hline
\end{tabular}

$n=$ number of patients for whom each parameter was analysed.

Prothrombin Time (PT), International Normalized Ratio (INR), Partial Thromboplastin Time (PTT), Aspartate aminotransferase (GOT), Alanine aminotransferase (GPT), Lactate dehydrogenase (LDH).

Table 4: Follow-up results.

\begin{tabular}{|l|c|}
\hline \multicolumn{1}{|c|}{ Outcome } & Count (\%) \\
\hline Deceased & $13(23.2)$ \\
\hline Discharged & $43(76.8)$ \\
\hline
\end{tabular}

among deceased patients, and neutrophil and lymphocyte counts were significantly higher among deceased patients than in discharged patients. As for the parameters associated with coagulation time, the differences were only significant in the case of INR, although higher values were observed in the deceased patient group.

\section{Discussion}

Although the COVID-19 pandemic represents a risk for the overall population, this risk is higher for immunocompromised patients, including those on chronic haemodialysis. These patients are more susceptible because of their older age and multiple co-morbidities, as documented by this research. The average age was 59.9 years old and, among the main co-morbidities, we found arterial hypertension (94.7\%), diabetes mellitus (30.4\%), heart disease (19.7\%), COPD $(12.5 \%)$ and obesity $(7.1 \%)$ [12]. Findings are consistent with reports from other studies where arterial hypertension is present in over $80 \%$ of patients undergoing haemodialysis treatment and $40 \%$ of patients with diabetes mellitus. These two conditions are the main causes for chronic kidney disease, both in our study sample and in the medical literature [13-15].

Furthermore, previous studies have shown that the presence of these same co-morbidities is usually associated with a worse prognosis for renal patients. As observed in our study, in the case of those patients also having COVID-19, COPD was the co-morbidity most significantly associated with death. This is in line with other publications, including those including COPD and COVID-19 patients that show a $60 \%$ mortality rate in comparison with the $55 \%$ mortality rate in patients without COPD [16].

In contrast, $50 \%$ of patients without previous renal disease who were admitted to the ICU were diagnosed with COPD as co-morbidity [17]. Moreover, residual renal function was present in $37.5 \%$ of cases, although no significant relation with mortality was found despite the fact that it reduces the constant inflammation that patients face on haemodialysis [18].

Among the most frequent clinical manifestations, we found dyspnea (85.7\%), fever (53.6\%), nonproductive cough (41.1\%), fatigue 
Table 5: Comparison of characteristics according to outcome.

\begin{tabular}{|c|c|c|c|c|c|}
\hline \multirow{2}{*}{$\begin{array}{ll}\text { Che, Median (IQR) } & \\
\text { Agacteristics }\end{array}$} & \multicolumn{2}{|c|}{ Deceased $(n=13)$} & \multicolumn{2}{|c|}{ Discharged $(n=43)$} & \multirow{2}{*}{$\begin{array}{c}\text { p-value } \\
0.264\end{array}$} \\
\hline & 67.0 & $(56.5-71.0)$ & 59.0 & $(50.0-69.0)$ & \\
\hline Sex (male), n (\%) & 11 & $(85.0)$ & 26 & $(60.0)$ & 0.181 \\
\hline \multicolumn{6}{|l|}{ Comorbidities, n (\%) } \\
\hline DBT & 4 & $(30.8)$ & 13 & $(30.2)$ & 0.999 \\
\hline HBP & 13 & $(100.0)$ & 40 & (93.0) & 0.999 \\
\hline Heart disease & 5 & $(38.5)$ & 6 & $(14.0)$ & 0.104 \\
\hline Obesity & 1 & $(7.7)$ & 3 & $(7.0)$ & 0.999 \\
\hline COPD & 4 & $(30.8)$ & 3 & (7.0) & $0.043(*)$ \\
\hline \multicolumn{6}{|c|}{ Symptoms at the moment of diagnosis, $n(\%)$} \\
\hline Fever & 7 & $(53.8)$ & 23 & $(53.5)$ & 0.999 \\
\hline Nonproductive cough & 6 & $(46.2)$ & 17 & (39.5) & 0.753 \\
\hline Productive cough & 2 & $(15.4)$ & 8 & $(18.6)$ & 0.999 \\
\hline Headache & 4 & $(30.8)$ & 2 & $(4.6)$ & $0.021(*)$ \\
\hline Diarrhea & 1 & $(7.7)$ & 4 & (9.3) & 0.999 \\
\hline Vomiting & 3 & $(23.1)$ & 4 & $(9.3)$ & 0.334 \\
\hline Dyspnea & 11 & $(84.6)$ & 37 & (86.0) & 0.999 \\
\hline Fatigue & 7 & $(53.8)$ & 11 & $(25.6)$ & 0.089 \\
\hline Myalgia & 6 & $(46.2)$ & 7 & $(16.3)$ & 0.055 \\
\hline Ageusia & 0 & $(0.0)$ & 5 & (11.6) & 0.580 \\
\hline Anosmia & 0 & $(0.0)$ & 4 & $(9.3)$ & 0.563 \\
\hline \multicolumn{6}{|l|}{ Co-RADS classification, n (\%) } \\
\hline 1 & 0 & $(0.0)$ & 5 & $(11.6)$ & 0.379 \\
\hline 3 & 0 & $(0.0)$ & 5 & (11.6) & \\
\hline 4 & 4 & $(30.8)$ & 9 & $(20.9)$ & \\
\hline 5 & 9 & $(69.2)$ & 24 & $(55.8)$ & \\
\hline \multicolumn{6}{|l|}{ Assisted ventilation, $\mathbf{n}(\%)$} \\
\hline Invasive mechanical & 3 & $(23.1)$ & 2 & $(4.6)$ & 0.070 \\
\hline Noninvasive & 8 & $(61.5)$ & 10 & $(23.2)$ & $0.017(*)$ \\
\hline \multicolumn{6}{|l|}{ Laboratory, Median (IQR) } \\
\hline White blood cells & 3300.0 & $(8.1-7300.0)$ & 9360.0 & $(4925.0-12297.5)$ & $0.040(*)$ \\
\hline Neutrophils & 7298.0 & $(4112.0-11058.8)$ & 90.3 & $(69.8-4949.3)$ & $0.008(*)$ \\
\hline Lymphocytes & 667.0 & $(454.0-978.8)$ & 214.5 & $(20.9-925.0)$ & $0.007(*)$ \\
\hline D-dimer & 700.0 & $(246.0-2803.5)$ & 362.5 & $(10.0-1827.3)$ & 0.132 \\
\hline C-Reactive Protein & 30.4 & $(14.0-53.5)$ & 33.0 & $(6.3-55.5)$ & 0.476 \\
\hline LDH & 402.5 & $(272.5-839.4)$ & 416.7 & $(302.9-541.7)$ & 0.999 \\
\hline Ferritin & 808.5 & $(131.4-1686.0)$ & 462.9 & $(211.3-1220.6)$ & 0.999 \\
\hline PT & 14.5 & $(12.4-17.0)$ & 12.0 & $(11.2-13.9)$ & 0.173 \\
\hline INR & 1.1 & $(1.1-542)$ & 1.0 & $(1.0-1.0)$ & $0.006(*)$ \\
\hline TTP & 34.0 & $(28.8-46.2)$ & 31.6 & $(30.0-39.2)$ & 0.173 \\
\hline
\end{tabular}

$(*)$ Significant at $5 \%$.

HBP: Arterial hypertension, DBT: Diabetes Mellitus, COPD: Chronic Obstructive Pulmonary Disease, Prothrombin Time (PT), International Normalized Ratio (INR), Partial Thromboplastin Time (PTT), Aspartate aminotransferase) (GOT), Alanine aminotransferase (GPT), Lactate Dehydrogenase (LDH).

(32.1\%), myalgia $(23.2 \%)$ and, less frequently, vomiting $(12.5 \%)$, headache (10.7\%), diarrhea (8.9\%), ageusia (8.9\%) and anosmia (7.1\%). This is in line with other studies about the frequency of the main manifestations. However, values are lower for gastrointestinal tract-associated symptoms and well below the reported values for the general population regarding taste and smell (34\%-87\%) [19-21]. It is striking that fever is the main symptom registered for the general population, reaching $99 \%$ of cases. However, it was less frequent among our patients, possibly because of the association with a lower immune response [22].
Regarding X-ray patterns, we used the CO-RADS classification. Approximately $59 \%$ of the X-rays were inside CO-RADS-5, turning CO-RADS-6 once reported PCR positive. This correlates to what is typically observed in radiological findings of alveolar-interstitial patterns and frosted glass images [11,23].

Regarding the standard laboratory tests of the patients, we found a significant association to leukopenia at the expense of lymphopenia, which could be explained because the constant state of uraemia leads to the deterioration of the immune function and response. Moreover, 
lymphopenia is a marker for poor prognosis [16,24]. Additionally, there is a significant association between mortality and high INR, which could be explained by sepsis-induced coagulopathy in these patients [25]. Nonetheless, there was no association with the complementary tests that are typically described in the literature for COVID- 19 .

Furthermore, $19.6 \%$ of cases required hospitalization in the ICU, $8.9 \%$ mechanical ventilation and $23.2 \%$ of the total patients that died. These findings bring additional evidence to the findings of some Spanish and Italian medical centers that showed that dialysis type chronic kidney disease represents a very poor prognosis in those patients who develop SARS-CoV-2 infection, with a mortality rate of $28 \%$ which is well over the estimated $1 \%-2 \%$ for the general population [5,26].

Preliminary studies in China had claimed that patients undergoing haemodialysis did not represent a vulnerable group due to their incapacity to create an immune response that leads to cytokine storm. Some metanalysis studies support that patients with kidney failure in terminal stage dialysis are highly susceptible to COVID-19 due to their immunosuppression [27-29]. Some authors suggest that the death of these patients is not directly related to the infection but other causes [26].

Our findings show that, in the studied population of patients undergoing permanent haemodialysis, these have a higher risk of contracting and developing severe forms of COVID-19. We also found that a great percentage of cases lead to death, which could be due to the immune changes induced by chronic uraemia, which lowers the activity of neutrophils, monocytes, $T$ cells and $B$ cells $[26,30]$.

The absence of effective treatments with proven evidence requires strengthening healthcare, biosecurity, individual and social measures that allow creating the most adequate protection, global health care measures and prevention against the COVID-19 pandemic; while the vaccine and their mid-term and long-term results are evaluated. It is essential to establish all necessary measures inside nephrology services and dialysis centers to protect patients and healthcare providers, avoiding risky transfers, crowded waiting rooms, maintaining distance among chairs, using personal protection equipment for personnel and patients (according to regulations) and medical isolation when there are SARS-CoV-2 infection symptoms or there has been a close contact. If the patient requires hospitalization, it is also necessary to speed up all interventions that could save the life of the patient, above all ensuring the correct oxygen saturation in blood, strictly following up the clinical and laboratory variables so that we can anticipate the appearance of severe multiorgan alterations. This will allow patients to receive the available therapeutic measures with proven evidence.

\section{Conclusion}

As a result of the data disclosed and the obtained correlations, it is possible to conclude that patients having permanent chronic kidney disease on dialysis are more vulnerable to develop complications and die due to COVID-19. This possibility increases in patients with additional chronic diseases such as hypertension and diabetes mellitus. Therefore, it is especially necessary to create strategies for the protection and individual care in patients with COPD because of the closer relationship observed in our research among this chronic condition (stage 5 renal disease in haemodialysis), COVID-19 and death.

\section{Acknowledgements}

No funding was received for this study.

\section{Conflict of Interest}

The authors of this article declare that there is no conflict of interest.

\section{References}

1. Asim M, Alkadi M, Hamad A, Othman M, Abuhelaiqa A, et al. (2020) Restructuring nephrology services to combat COVID-19 pandemic: Report from a Middle Eastern country. World J Nephrol 9: 9-17.

2. Al-Rohaimi AH, Al Otaibi F (2020) Novel SARS-CoV-2 outbreak and COVID19 disease; a systemic review on the global pandemic. Genes Dis 7: 491-501.

3. Wu Z, McGoogan JM (2020) Characteristics of and Important Lessons from the Coronavirus Disease 2019 (COVID-19) Outbreak in China: Summary of a Report of 72314 Cases from the Chinese Center for Disease Control and Prevention. JAMA 323: 1239-1242.

4. Khosroshahi HT, Mardomi A, Niknafs B, Farnood F, Shekarchi M, et al. (2020) Current status of COVID-19 among hemodialysis patients of East Azarbaijan Province of Iran. Hemodial Int 25: 214-219.

5. Résimont G, Dubois B, Grosch S, Bovy C, Collart F, et al. (2020) La dialyse chronique face á la COVID-19. Rev Med Liege 75: S41-S47.

6. Goicoechea M, Sánchez Cámara LA, Macías N, de Morales AM, Rojas AG, et al. (2020) COVID-19: clinical course and outcomes of 36 hemodialysis patients in Spain. Kidney Int 98: 27-34.

7. Radhakrishnan Y, Hassanein M, Stephany B (2020) Management of COVID-19 in special populations with kidney disease. Cleve Clin J Med.

8. Hsu CM, Weiner DE (2020) COVID-19 in dialysis patients: outlasting and outsmarting a pandemic. Kidney Int 98: 1402-1404.

9. Herrera-Añazco P, Rabanal CL, Benites-Zapata VA (2020) Are the Latin American recommendations for the management of patients infected with COVID -19 on hemodialysis realistic in health systems with limited resources? J Bras Nefrol 42: 502-503.

10. Depine SÁ, Aroca GM (2018) Desafiando a La Inequidad de Latinoamérica: Estrategias Facilitadoras de "Control" de La Enfermedad Renal Crónica. Ediciones Universidad Simón Bolívar, Colombia.

11. Smithuis F, Smithuis R (2020) 32 cases of suspected COVID-19 Imaging findings and follow up. Radiology Assistant.

12. Arslan H, Musabak U, Ayvazoglu Soy EH, Azap OK, Sayin B, et al. (2020) Incidence and immunologic analysis of coronavirus disease (COVID-19) in hemodialysis patients: A single-center experience. Exp Clin Transplant 18: 275-283.

13. Loutradis CN, Tsioufis C, Sarafidis PA (2017) The Clinical Problems of Hypertension Treatment in Hemodialysis Patients. Curr Vasc Pharmacol 16: 54-60.

14. Khatib ST, Hemadneh MK, Hasan SA, Khazneh E, Zyoud SH (2018) Quality of life in hemodialysis diabetic patients: A multicenter crosssectional study from Palestine. BMC Nephrol 19: 49.

15. Kidney Disease: Improving Global Outcomes (2013) KDIGO 2012 Clinical Practice Guideline for the Evaluation and Management of Chronic Kidney Disease. Kidney Int Suppl 3.

16. Yang $X, Y u$ Y, Xu J, Shu H, Xia J, et al. (2020) Clinical course and outcomes of critically ill patients with SARS-CoV-2 pneumonia in Wuhan, China: a single-centered, retrospective, observational study. Lancet Respir Med 8: 475-481.

17. Ejaz H, Alsrhani A, Zafar A, Javed H, Junaid K, et al. (2020) COVID-19 and comorbidities: Deleterious impact on infected patients. J Infect Public Health 13: 1833-1839. 
18. Mathew AT, Fishbane S, Obi Y, Kalantar-Zadeh K (2016) Preservation of residual kidney function in hemodialysis patients: reviving an old concept. Kidney Int 90: 262-271.

19. Tian S, Hu N, Lou J, Chen K, Kang X, et al. (2020) Characteristics of COVID-19 infection in Beijing. J Infect 80: 401-406.

20. Goyal P, Choi JJ, Pinheiro LC, Schenck EJ, Chen R, et al. (2020) Clinical Characteristics of Covid-19 in New York City. N Engl J Med 382: 23722374.

21. Spinato G, Fabbris C, Polesel J, Cazzador B, Borsetto D, et al. (2020) Alterations in Smell or Taste in Mildly Symptomatic Outpatients With SARS-CoV-2 Infection. JAMA 323: 2089-2090.

22. Stefan G, Mehedinti AM, Andreiana I, Zugravu AD, Cinca S, et al. (2021) Clinical features and outcome of maintenance hemodialysis patients with COVID-19 from a tertiary nephrology care center in Romania. Ren Fail 43: 49-57.

23. Gravell RJ, Theodoreson MD, Buonsenso D, Curtis J (2020) Radiological manifestations of COVID-19: key points for the physician. Br J Hosp Med (Lond) 81: 1-11.

24. Wang R, Liao C, He H, Hu C, Wei Z, et al. (2020) COVID-19 in Hemodialysis Patients: A Report of 5 Cases. Am J Kidney Dis 76: 141143.
25. Windyga J (2020) COVID-19 a zaburzenia hemostazy. Med Prakt 7 59-68.

26. Flythe JE, Assimon MM, Tugman MJ, Chang EH, Gupta S, et al. (2020) Characteristics and Outcomes of Individuals With Pre-existing Kidney Disease and COVID-19 Admitted to Intensive Care Units in the United States. Am J Kidney Dis 77: 190-203.

27. Huang C, Wang Y, Li X, Ren L, Zhao J, et al. (2020) Clinical features of patients infected with 2019 novel coronavirus in Wuhan, China. Lancet 395: 497-506.

28. Khoo BZE, See YP, Koh TJK, Yeo SC (2020) Coronavirus Disease 2019 (COVID-19) and Dialysis: The Experience in Singapore. Kidney Med 2: 381-384.

29. Tang B, Li S, Xiong Y, Tian M, Yu J, et al. (2020) COVID-19 Pneumonia in a Hemodialysis Patient. Kidney Med 2: 354-358.

30. Ando M, Shibuya A, Tsuchiya K, Akiba T, Nitta K (2006) Reduced expression of Toll-like receptor 4 contributes to impaired cytokine response of monocytes in uremic patients. Kidney Int 70: 358-362. 